\title{
The effect of branched-chain amino acids (BCAA) on meal pattern of rats
}

\author{
Omar Obeid, Nabiha Ramadan and Nahla Hwalla \\ American University of Beirut, Beirut, Lebanon
}

BCAA (isoleucine, leucine and valine) have been reported to enhance food intake and have been used as anti-anorectic agents, especially in critically-ill patients ${ }^{(1)}$. However, it is not clear whether their stimulatory effect on food intake is the result of an increase in meal size and/or meal number. Furthermore, the impact of individual BCAA on food intake is not well documented.

The present experiment was designed to investigate the effect of individual BCAA on meal patterns of rats. Twenty-four adult male Sprague-Dawley rats were randomly divided into four equal groups and fed control diet or diets supplemented with isoleucine, leucine or valine $(50 \mathrm{~g} / \mathrm{kg})$. Feeding patterns were monitored for 2 weeks using feed recording equipment (model 80350 series; Campden Instruments Limited, Lafayette, IN, USA) $)^{(2)}$.

\begin{tabular}{|c|c|c|c|c|c|c|c|c|c|}
\hline & \multicolumn{2}{|c|}{ Control } & \multicolumn{2}{|c|}{ Valine } & \multicolumn{2}{|c|}{ Isoleucine } & \multicolumn{2}{|c|}{ Leucine } & \multirow[b]{2}{*}{$P($ ANOVA $)$} \\
\hline & Mean & $\mathrm{SE}$ & Mean & $\mathrm{SE}$ & Mean & $\mathrm{SE}$ & Mean & $\mathrm{SE}$ & \\
\hline Food intake (g) & 18.8 & 0.35 & 19.8 & 0.75 & 19.0 & 0.32 & 18.8 & 0.48 & 0.46 \\
\hline Meal size $(\mathrm{g})$ & $1.78^{\mathrm{a}}$ & 0.05 & $2.80^{\mathrm{b}}$ & 0.10 & $2.16^{\mathrm{c}}$ & 0.06 & $1.98^{\mathrm{c}}$ & 0.07 & 0.001 \\
\hline Meal number & $10.9^{\mathrm{a}}$ & 0.29 & $7.24^{\mathrm{b}}$ & 0.21 & $9.02^{\mathrm{c}}$ & 0.20 & $9.97^{\mathrm{d}}$ & 0.28 & 0.001 \\
\hline Meal duration (s) & 568 & 20.8 & $1036^{\mathrm{a}}$ & 75.9 & 536 & 15.4 & 542 & 23.1 & 0.001 \\
\hline Feeding rate $(\mathrm{mg} / \mathrm{s})$ & 3.74 & 0.25 & 3.76 & 0.25 & 4.21 & 0.12 & 4.17 & 0.30 & 0.34 \\
\hline
\end{tabular}

$\overline{\mathrm{a}, \mathrm{b}, \mathrm{c}, \mathrm{d}}$ Mean values in the same row with unlike superscript letters were significantly different (Fisher's post-hoc test; $P<0.05$ )

Total food intake and feeding rate were similar among the different groups. The meal size of rats maintained on diets supplemented with individual BCAA was higher than that of the control group and this increase was highly pronounced in the valine-supplemented-diet group. In contrast, the meal number of rats maintained on individual-BCAA-supplemented diets was lower than that of the control group. Meal duration was similar between the control, leucine and isoleucine groups, while that of the valine group was higher.

The mechanism (s) by which individual BCAA affect meal pattern is not clear and may relate to a competition with tryptophan for entry into the brain, thus reducing the production of the satiating neurotransmitter serotonin. In addition, the limited hepatic capacity for BCAA metabolism may be involved in food intake regulation, especially as increased liver ATP has been reported to decrease appetite and stimulate meal termination ${ }^{(3)}$. In conclusion, individual BCAA were found to affect meal pattern of rats and this effect seems to vary between the different BCAA, of which valine showed the most potent effect.

1. Lavianoa A, Muscaritoli M, Cascino A, Preziosa I, Inui A, Mantovani G \& Rossi-Fanelli F (2005) Curr Opin Clin Nutr Metab Care 8, $408-414$.

2. Bassil MS, Hwalla H \& Obeid OA (2007) Obesity 15, 616-623.

3. Ji H \& Friedman MI (1999) Physiol Behav 68, 181-186. 